\title{
Experimental Study on Medium Viscosity Oil Displacement Using Viscoelastic Polymer
}

\author{
Huiying Zhong $\mathbb{D}$, Qiuyuan Zang $\mathbb{D}^{D}$, Hongjun Yin $(\mathbb{D}$, and Huifen Xia $(\mathbb{D})$ \\ Key Laboratory for Enhanced Oil \& Gas Recovery of the Ministry of Education, Northeast Petroleum University, \\ Daqing 163318, China \\ Correspondence should be addressed to Huiying Zhong; zhhy987@126.com
}

Received 20 August 2018; Revised 24 October 2018; Accepted 28 October 2018; Published 29 November 2018

Academic Editor: Shengnan Nancy Chen

Copyright ( 2018 Huiying Zhong et al. This is an open access article distributed under the Creative Commons Attribution License, which permits unrestricted use, distribution, and reproduction in any medium, provided the original work is properly cited.

\begin{abstract}
With the growing demand for oil energy and a decrease in the recoverable reserves of conventional oil, the development of viscous oil, bitumen, and shale oil is playing an important role in the oil industry. Bohai Bay in China is an offshore oilfield that was developed through polymer flooding process. This study investigated the pore-scale displacement of medium viscosity oil by hydrophobically associating water-soluble polymers and purely viscous glycerin solutions. The role and contribution of elasticity on medium oil recovery were revealed and determined. Comparing the residual oil distribution after polymer flooding with that after glycerin flooding at a dead end, the results showed that the residual oil interface exhibited an asymmetrical " $U$ " shape owing to the elasticity behavior of the polymer. This phenomenon revealed the key of elasticity enhancing oil recovery. Comparing the results of polymer flooding with that of glycerin flooding at different water flooding sweep efficiency levels, it was shown that the ratio of elastic contribution on the oil displacement efficiency increased as the water flooding sweep efficiency decreased. Additionally, the experiments on polymers, glycerin solutions, and brines displacement medium viscosity oil based on a constant pressure gradient at the core scale were carried out. The results indicated that the elasticity of the polymer can further reduce the saturation of medium viscosity oil with the same number of capillaries. In this study, the elasticity effect on the medium viscosity oil interface and the elasticity contribution on the medium viscosity oil were specified and clarified. The results of this study are promising with regard to the design and optimum polymers applied in an oilfield and to an improvement in the recovery of medium viscosity oil.
\end{abstract}

\section{Introduction}

According to BP's "Statistical Review of World Energy" data, oil prices have decreased from 2014 [1-3]. However, with the rapid growth in energy demand and a depletion of conventional oil, the development of nonconventional energy sources, such as viscous oil, bitumen, and shale oil, is significant for the entire petroleum industry [4-6]. The viscous oil is mainly distributed in many basins, especially in the region of Middle East, North America, and South America $[7,8]$. Reports by the U.S. Department of Energy showed that $40 \%$ of the $900-1300$ billion barrels of reserves in the world is viscous oil and ultraheavy oil $[9,10]$. The popular development technique of heavy oil is thermal process; however, it is limited by many factors. The polymer flooding is the other main technique for exploiting heavy oil. Amirian et al. reviewed the half-century heavy oil polymer flooding application, including the universal country distribution, polymer types, development effects, onshore or offshore projects, and well types [11]. In China, viscous oil is a rich resource, mainly distributed in the Liaohe oilfield, Shengli oilfield, and Bohai offshore oilfield [12-15]. Based on many different experiments, some researchers have come to believe that viscous oil with a viscosity of below $100 \mathrm{mPa} \cdot \mathrm{s}$ and an oil saturation of above $30 \%$ is suitable for polymer flooding technique to enhance oil recovery (EOR); moreover, the permeability of the reservoir is above $20 \times 10^{-3} \mu \mathrm{m}^{2}$, the thickness of the oil layers is above $3 \mathrm{~m}$, and the temperature of the reservoir is under $90^{\circ} \mathrm{C}$ [16-20]. However, Sheng et al. presented that there are nine oilfields in the world that have 
carried out polymer flooding in which the oil viscosity is greater than $100 \mathrm{mPa} \cdot \mathrm{s}$ [21]. As early as 1977, two researchers from the Marathon Oil Company investigated the polymer displacement process of viscous oil and injected polyacrylamide (PAM) polymers into Ottawa sand packs, where the permeability was $3700-5900 \times 10^{-3} \mu \mathrm{m}^{2}$ and the porosity was $35 \%[22,23]$. Two types of oil were used in their study, including Wyoming oil and refined oil, the viscosity of which was 220 and $1140 \mathrm{mPa} \cdot \mathrm{s}$, respectively. The recovery was 19$31 \%$, and the results showed that the polymer solutions enhanced the viscous oil recovery. Recently, there have been an increasing number of studies concentrating on the technique of polymer displacement of viscous oil [24-27], particularly in Canada, where viscous oil is quite rich [28-30]. However, the oil recovery has reached only $10 \%$ through water flooding in western Canada. To study the feasibility of polymer flooding process, Wassmuth et al. used three types of oil, namely, at 280,1600, and $780 \mathrm{mPa} \cdot \mathrm{s}$, respectively, and injected $0.5 \mathrm{PV}$ of clear water until the water cut approached $90 \%$ and then injected a $6.0 \mathrm{PV}$ polymer slug at a concentration of $1500 \mathrm{mg} / \mathrm{L}$, finally injecting 5.0 PV of clear water [31]. The experiment results showed that the recoveries of the three oil types increased $16 \%, 22 \%$, and $23 \%$, respectively. In China, offshore heavy oil resources have been estimated at 4 billion barrels, and Bohai Bay is one of the most important oil basins, the reserves of which account for twothirds, and $70 \%$ of which is viscous oil [32-34]. The viscosity of the crude oil in Bohai Bay basin is from 13 to $380 \mathrm{mPa} \cdot \mathrm{s}$, and the average viscosity is $70 \mathrm{mPa} \cdot \mathrm{s}$, which can be defined as medium viscosity oil [35-38]. Therefore, the development of an offshore oilfield is significant for the maximum utilization of oil resources. As of 2013, there were ten blocks using polymer flooding or alkali-surfactant-polymer (ASP) flooding in the Bohai Bay offshore oilfield, covering reserves of approximately 5.7 billion barrels [37, 39, 40]. The polymers used in viscous oil field development including hydrophobically modified partially hydrolyzed polyacrylamides (HMHPAMs) and partially hydrolyzed polyacrylamide (HPAM). Comparing with HPAM, the resistance factors and residual resistance factors produced by HMHPAMs are higher than those of HPAM due to an increase of aggregate size of HMHPAMs. The microdisplacement experiments indicated that the HMHPAMs could move deep into the porous media of reservoirs [7]. Moreover, the existing literature also reported that HMHPAMs had more stable displacement front and easily formed a piston-like displacement. The keys depended on what polymer viscosity injected and when the polymer injection should be reduced or stopped; the extensive review of polymer flooding in many oil fields are presented elsewhere $[7,11,16,41]$. The polymer viscosity, concentration, and slug size employed in the viscous oil field application were also discussed and considered. Furthermore, the injection strategies were performed in the low oil price environment. If possible, a simulator is necessary for a petroleum engineer to forecast the future performance in heavy oil with polymer flooding. After utilizing an extensive data set of polymer flooding process in a heavy oil field, Amirian et al. developed a data-driven modeling method to forecast the potential performance in polymer flooding heavy oil reservoirs. This work is beneficial to accelerate the real-time decision making workflows for the reservoir management teams [11].

Based on a core experiment and a pilot test, in 2008, Aktas and Clemens used two-dimensional etched-silicon micromodels simulating a porous medium, carrying out brine, conventional polymers, and associative polymers at the same concentration displacement as medium viscosity oil $(200 \mathrm{mPa} \cdot \mathrm{s})$, the results of which indicated that the associative polymers did not act as a plug and showed a stable front; therefore, an associative polymer can improve the sweep efficiency compared with brine and conventional polymer flooding process [42]. Considering for the silicon model can be visualized for the displacement process, Doorwar and Mohanty conducted water, polymer, and alkali-surfactant slug displacements of viscous oil in two-dimensional silicon micromodels in 2011, the mobility ratio of which was designed as 1, 100, 1000, and 10,000 [9, 43]. The surfactant flood increases with the surface of the water fingers. However, the polymer solutions have elastic characteristics, not only viscous characteristics, and a decrease in the residual oil saturation through polymer flooding using high viscoelasticity solutions has been widely concerned during the past few years [44-48]. Polymer transport in porous media is significantly influenced by rheological properties, such as the flow behavior index, dispersion coefficient, and consistency coefficient. The transport has different stage in the porous media, and the breakthrough of polymer solutions is mainly influenced by the flow behavior index [49]. Some researchers have validated the existence of elasticity using elastic modulus testing and then conducted water-glycerin-polymer flooding and water-polymer-glycerin flooding; here, the viscosity of the polymer is the same with that of glycerin $[50,51]$. The results indicated that the polymer solutions can further enhance the oil recovery after glycerin flooding. In contrast, the glycerin cannot further enhance the recovery after polymer flooding, and their study confirmed that the main factor of the polymer flooding process improving the microsweep efficiency is the elastic characteristics. Moreover, Xia et al. further conducted many studies and carried out glycerin and polymer solutions displacement of residual oil in dead ends, using the same viscosity for both displacement fluids, the results of which showed that an elastic polymer can reduce the residual oil saturation more than glycerin flooding and that a polymer solution can exhibit a "pull" and "tripping" on an oil blank and oil droplet [52, 53]. Nevertheless, Vermolen et al. conducted core experiments confirming that polymers of high elasticity can further reduce the residual oil saturation; however, for crude oil of a high viscosity ( $300 \mathrm{mPa} \cdot \mathrm{s})$, hardly any effect from an increase in the viscoelasticity was observed with regard to the oil recovery [54].

In this study, we carried out microvisual and core flooding experiments, comparing the polymer displacement characteristics in medium viscosity oil with glycerin flooding, using the same viscosity of the polymer solutions, and analyzed the mechanism of the elasticity effect on medium viscosity oil recovery, concluding that the elasticity contributes to oil recovery after water flooding at a different water 


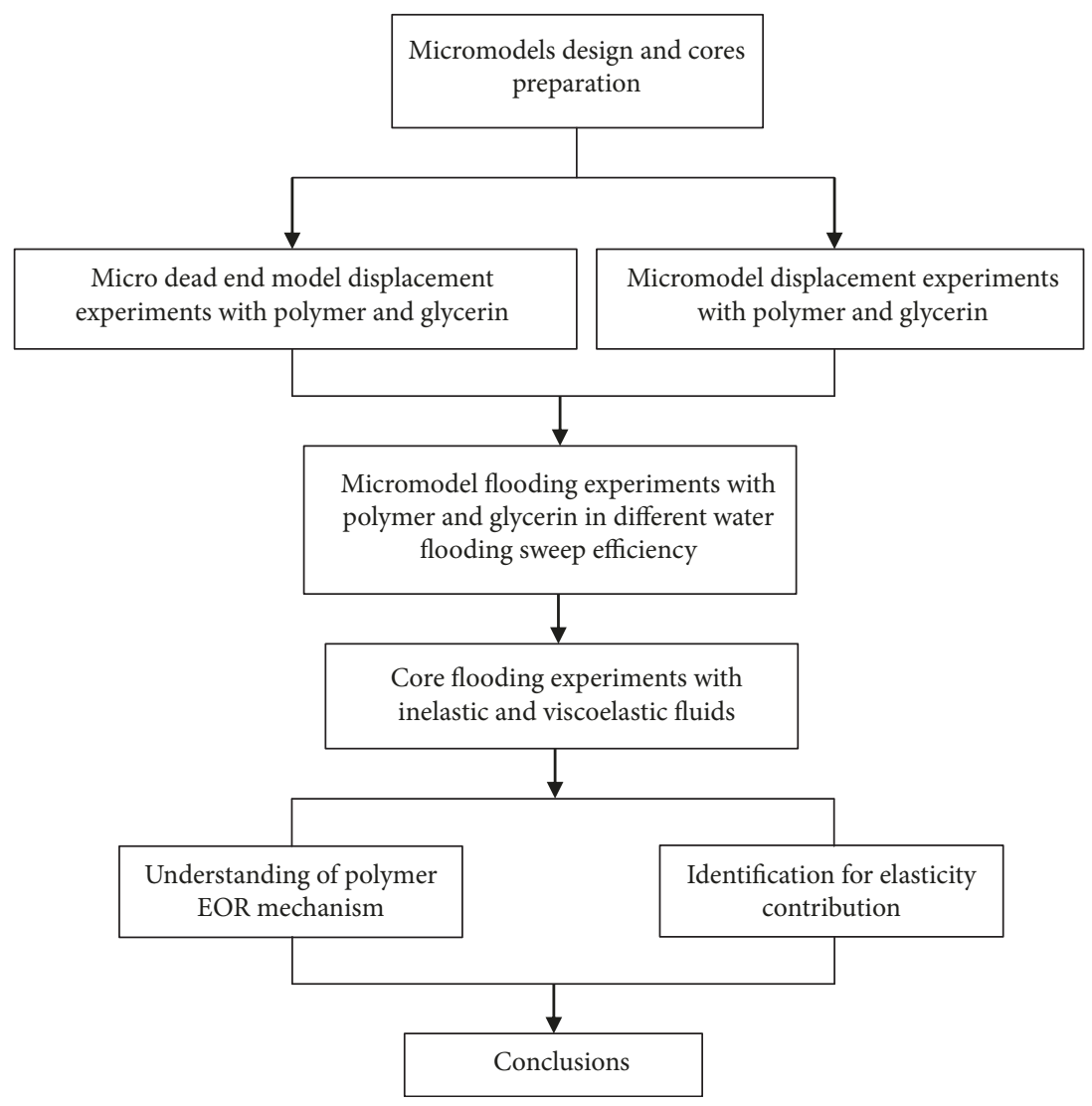

FIGURE 1: General sketch of this experimental study.

sweep efficiency. Furthermore, these results were validated using reliable core experiments. The purpose of this study is to reveal the mechanism of elastic polymer enhancing medium viscosity oil recovery and identify the quantitative contribution of elasticity on the oil recovery. All the findings will provide a theoretical basis for the design of an optimum polymer solution applied to an oilfield.

In this present study, the displacement performance of medium viscosity oil with viscoelastic polymer was experimentally investigated. The general sketch of this experimental study can be illustrated in Figure 1. First, the micromodels employed in the experiments were demonstrated. Then, the experiments in a micro dead-end model were carried out, and the results were discussed. After that, the micromodel experiments with different elastic displacement fluids were performed in different degrees of water flooding, and the role of viscoelasticity in polymer flooding process was worked out. Finally, the core experiments were carried out with the inelastic and viscoelastic fluids flooding, and then the contribution of elasticity on the enhanced oil recovery was identified.

\section{Microvisual Experiments}

2.1. Experimental Models. In this study, we used two etchedglass models to observe the phenomena affecting viscous oil displacement. Figure 2(a) shows a micromodel with dead ends, whose dimensions are $40 \mathrm{~mm}^{2}$. There are five main flow channels, with ten dead ends in every main flow channel. The width of the dead ends is from 200 to $500 \mu \mathrm{m}$, and the depth is from 300 to $500 \mu \mathrm{m}$, with the fluid flow from the left side to the right side. The other model is a simulation model, as shown in Figure 2(b), the total size of which is $40 \mathrm{~mm}^{2}$, with a permeability of $2500 \times 10^{-3} \mu \mathrm{m}^{2}$, and maximum pore and minimum pore radii of roughly 500 and $5 \mu \mathrm{m}$, respectively. The fluid flows in from the lower-right corner and flows out of the upper-left corner. The pore-size distribution and permeability approximate those of the Bohai Bay reservoir. Both models are transparent. The models can reflect the geometrical and topological aspects of a real porous medium.

2.2. Experimental Equipment and Materials. As shown in Figure 3, the microvisual experimental equipment includes a stress-controlled rheometer, etched-glass models, micro plunger pump, and high-resolution imaging and analysis system. During the experiment, we used a high-resolution camera to rack the flow behavior of the fluids in the micromodel. The imaging analysis system can translate the flow image for different flow times into a computational signal, and the imaging analysis can describe the flow characteristics of the polymer solution in the displacement of viscous oil and can calculate the corresponding oil saturation and displacement oil efficiency.

In this study, refined oil was collected, which is mixed with Bohai Bay crude oil without gas or diesel oil, and the 


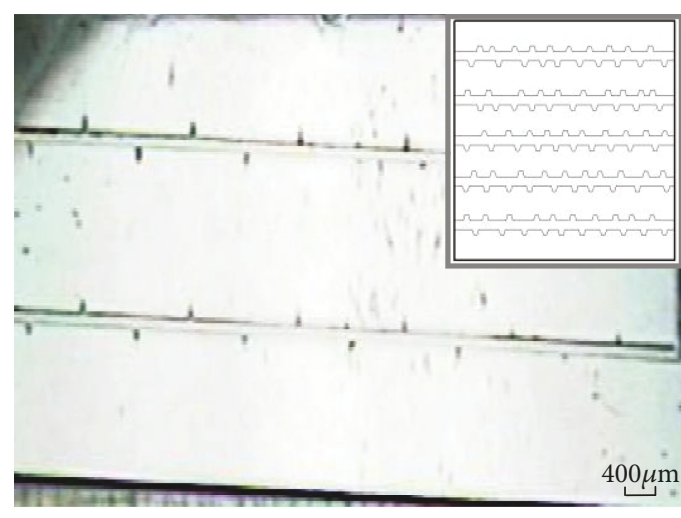

(a) Dead-end model

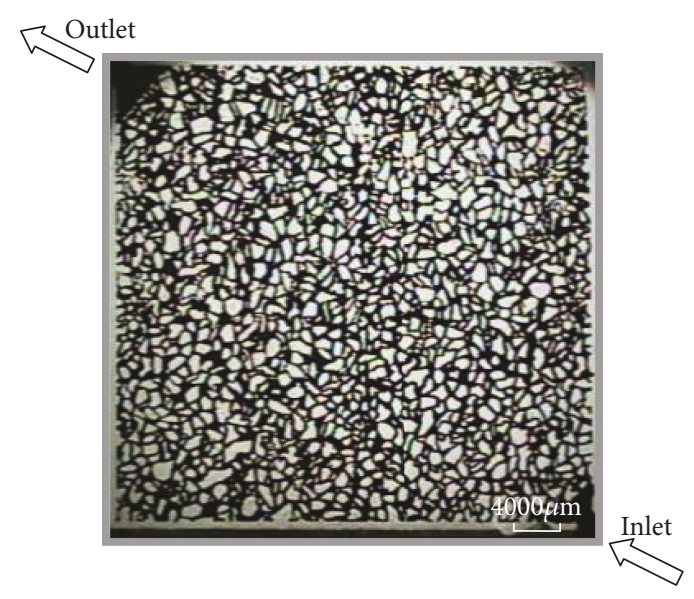

(b) Microsimulation model

FIGURE 2: Etched-glass physical models (both of the models are saturated with oil, the dark area represents oil, and the light area represents glass).

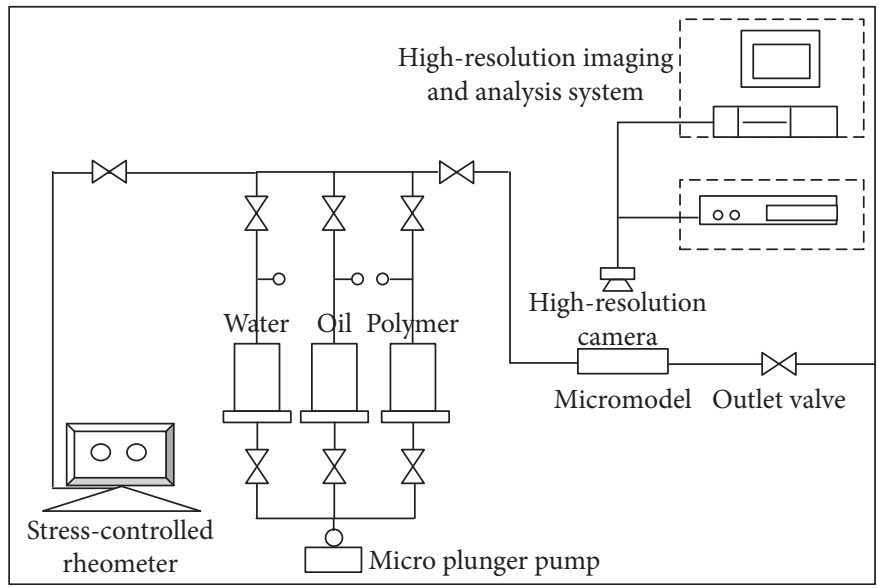

Figure 3: Schematic illustration of the equipment used in the microvisual displacement experiments.

viscosity is $70 \mathrm{mPa} \cdot \mathrm{s}$ at $30^{\circ} \mathrm{C}$. The synthetic brine was prepared using redistilled water, simulating the mineral composition of the formation water in the Bohai Bay offshore oilfield. The salinity of the brine is $9947.8 \mathrm{mg} / \mathrm{L}$. The displacement fluids include brine, glycerin, and AP-P4 hydrophobically associating water-soluble polymers with a relative molecular weight of $1.1 \times 10^{7} \mathrm{Da}$. The polymer solution was created using a mother liquid dilution method, with prepared concentrations of 1200,1000 , and $900 \mathrm{mg} / \mathrm{L}$ and a viscosity of 75,40 , and $20 \mathrm{mPa} \cdot \mathrm{s}$, respectively.

2.3. Experimental Results and Discussion. We investigated polymer and glycerin displacement medium viscosity oil, in which the viscosity of both displacement fluids is $40 \mathrm{mPa} \cdot \mathrm{s}$. The detailed procedure was as follows: after the micromodel was vacuumed, it was saturated with oil and undergoing isothermal aging; then polymer flooding process was performed; the flow rate was designed as 1.0 pore volume per hour $(\mathrm{PV} / \mathrm{h})$ and was applied until the oil can no longer be produced. Finally, the micromodel was washed and the other displacement fluid experiment was repeated.
Figures 4 and 5 show residual oil distribution images after viscoelastic polymer and glycerin flooding, respectively, where the dark shade is oil and the light shade is the displacement fluid.

As can be observed from Figures 4 and 5, the area of the red circle is dead end of the etched-glass model, and the residual oil saturation at the dead ends after polymer flooding is lower than that after glycerin flooding. The two solutions are the same in terms of viscosity, the reason for which is the elastic effect, and therefore the elasticity can reduce the oil saturation and then enhance the oil recovery. Moreover, the distribution characteristics of residual oil at dead ends indicate that the residual oil interface after polymer solution flooding presents an asymmetrical " $U$ " shape (Figures 4(a) and 4(b)). This can be attributed to the fact that the polymer has flexible long chain molecules, which will incur molecular twining during a flow, and the twining molecules will produce stretching characteristics, and then the upstream flow will take the oil along the wall and downstream, ultimately resulting in the oil downstream to be further displaced. This reveals that the oil interface moves deeper 


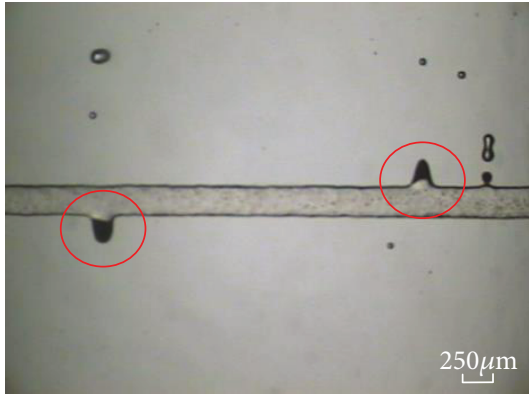

(a) \#1 Dead end

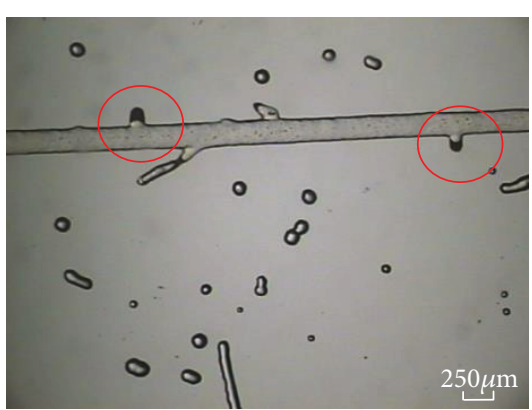

(b) \#2 Dead end

FIgURE 4: Distribution characteristics of residual oil at dead ends after viscoelastic polymer flooding (the dark area represents oil, and the lighter the color is, the lower the saturation is).

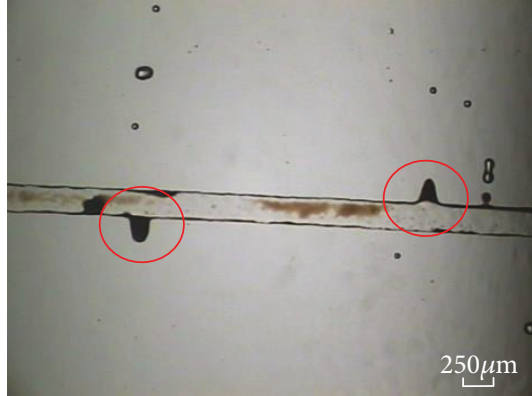

(a) \#1 Dead end

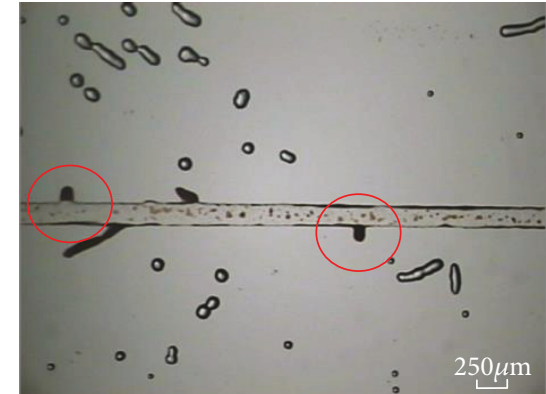

(b) \#2 Dead end

FIGURE 5: Distribution characteristics of residual oil at dead ends after glycerin flooding (the dark area is oil, and the lighter the color is, the lower the saturation is; the light area represents the displacing fluid).

toward the dead ends in the process of oil displacement by viscoelastic polymer solution. In contrast, the residual oil interface after glycerin flooding presents a symmetrical " $U$ " shape (Figures 5(a) and 5(b)), and the oil interface moves very shallow toward the dead ends in the displacement process. This is principally because purely viscous fluid incurs only a shear stress, where the stresses on the upstream and downstream flows are essentially symmetrical.

A series of similar microvisual experiments were performed using the microsimulation model as mentioned above (Figure 2(b)). There are two reasons to further employ the simulation model. Firstly, it is feasible to identify the ratio of elastic contribution on the oil recovery using the polymer displacement of viscous oil in microsimulation model. Secondly, it is reliable to determine the ratio of the elastic contribution on the oil recovery through the polymer injection after water flooding at stages with different sweep efficiency levels.

The experiments for identifying the elastic contribution on oil recovery were first carried out. Both glycerin and polymer solutions with the same viscosity were employed in this experiment, and the detailed procedure is the same as the above dead-end model experiments. Figures 6 and 7 show the residual oil distribution characteristics after viscoelastic polymer and glycerin flooding, respectively. Similarly, the dark shade in the images is the oil phase.

As can be seen in these images, the residual oil saturation is reduced during the displacement process. Comparing the residual oil saturation in viscoelastic polymer flooding with that in glycerin flooding, we can see that the oil saturation distribution after viscoelastic polymer flooding (Figures 6(b) and $6(\mathrm{c})$ ) is lower than that after glycerin flooding (Figures 7(b) and 7(c)) under the same initial saturation (Figures 6(a) and 7(a)). Because the same viscosity is employed, the oil saturation reduction owing to the elasticity behavior of the polymer solutions, that is, the displacement efficiency by viscoelastic polymer flooding, is higher than that of purely viscous glycerin flooding.

We can further use image processing method to calculate the medium viscosity oil recovery quantitatively, as shown in Table 1, where the oil recovery after polymer flooding increases $6.0 \%$ compared with that of glycerin flooding. The results also indicate that the ratio of elastic contribution on the oil recovery can reach $10.72 \%$, and the contribution of viscosity on the oil recovery is $89.28 \%$.

The actual viscous oil is developed on offshore oilfield by switching the injection polymer after water flooding, and therefore, based on the above direct polymer or glycerin flooding microvisual experiments, we carried out microvisual experiments for polymer or glycerin displacement of viscous oil at water flooding stages with different sweep efficiency of $20 \%, 40 \%$, and $60 \%$, and the elastic contribution to oil recovery after water flooding at different water sweep efficiencies was further identified.

Figure 8 shows the oil distribution characteristics after the injection of polymer solution or glycerin solution when 


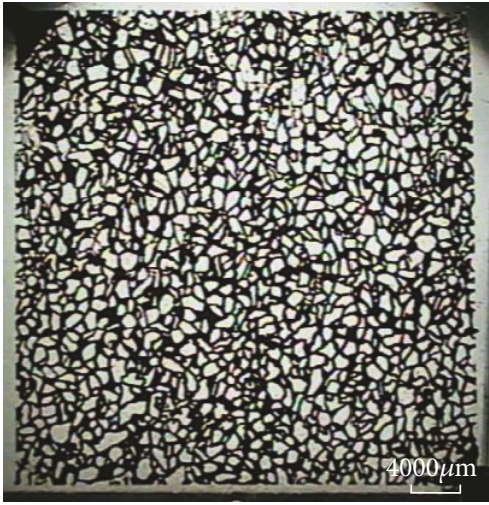

(a) Initial saturation with oil

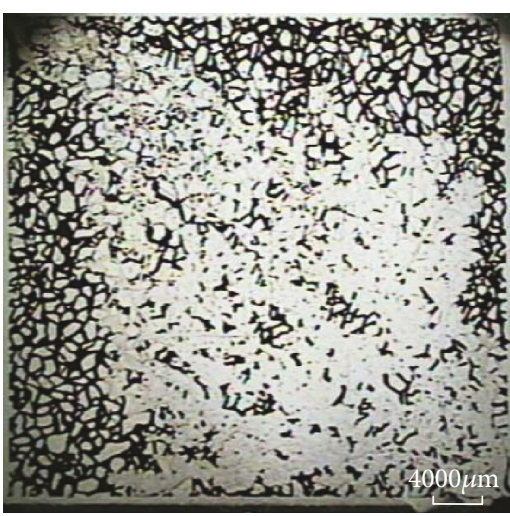

(b) Displacement process

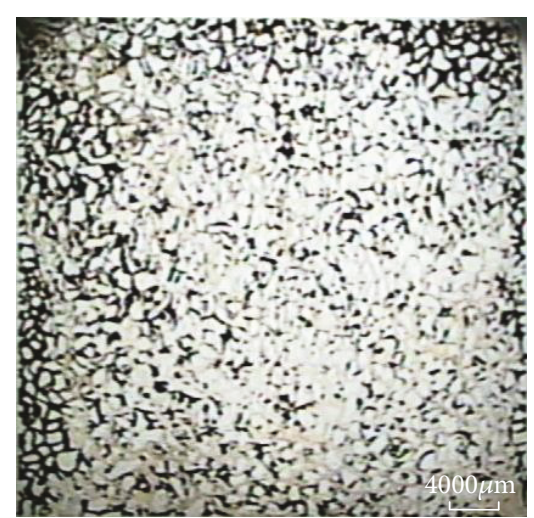

(c) Residual oil after polymer flooding

FIGURE 6: Oil distribution with viscoelastic polymer flooding in a simulation model (the dark area is oil, and the lighter the color is, the lower the saturation is; the light area represents the displacing fluid).

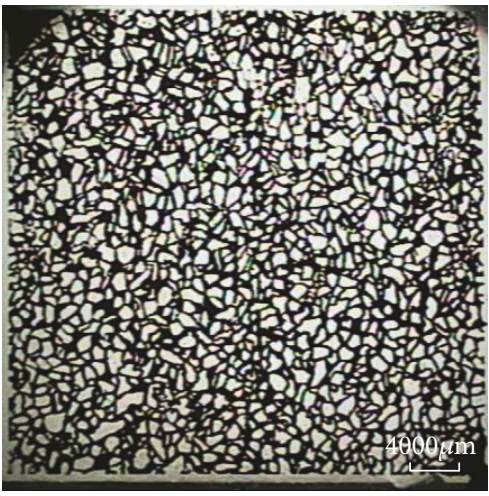

(a) Initial saturation with oil

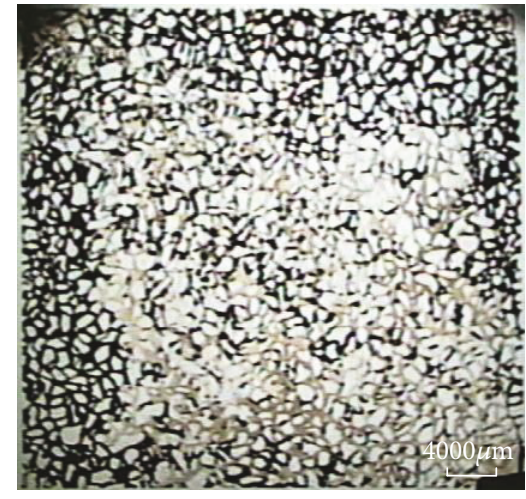

(b) Displacement process

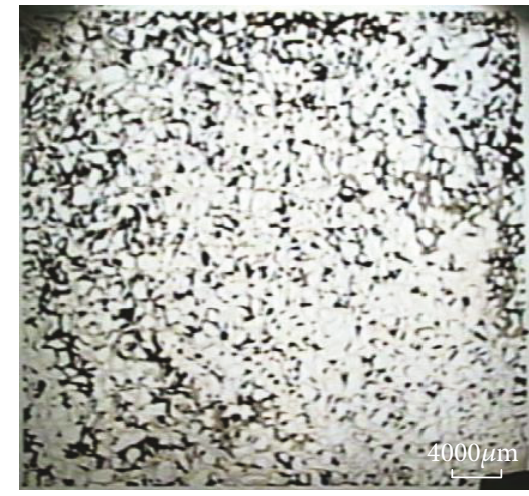

(c) Residual oil after glycerin flooding

FIGURE 7: Oil distribution with glycerin flooding in a simulation model (the dark area is oil, and the lighter the color is, the lower the saturation is; the light area represents the displacing fluid).

TABLE 1: Displacement results of glycerin and viscoelastic polymer with the same viscosity (40 mPa.s).

\begin{tabular}{lccc}
\hline Displacement fluid & Flow rate $(\mathrm{PV} / \mathrm{h})$ & Oil recovery $(\%)$ & Incremental oil recovery by elasticity $(\%)$ \\
\hline Glycerin solution & 1.0 & 50.0 & - \\
Viscoelastic polymer solution & & 56.0 & 6.0 \\
\hline
\end{tabular}

the water displacement sweep efficiency is $20 \%$. And Figure 9 shows the oil distribution characteristics after the injection of polymer solution or glycerin solution when the water displacement sweep efficiency is $60 \%$.

As shown in these images, the residual oil saturation after viscoelastic polymer flooding is reduced more than that after glycerin flooding under the same water displacement sweep efficiency. Similarly, as shown in Table 2, the corresponding displacement efficiency was calculated using the image processing method. The results indicate that the oil recovery differs based on polymer or glycerin displacement at different water sweep efficiency levels, and the ultimate oil recovery after glycerin or polymer flooding decreases as the water sweep efficiency increases. Compared with the ultimate oil recovery after glycerin flooding, the viscoelastic polymer solutions can enhance the oil recovery, that is, the elasticity can further improve the displacement efficiency. Under different water displacement sweep efficiency of $20 \%, 40 \%$, and $60 \%$, the ultimate oil recovery increases from $48.94 \%$, $47.26 \%$, and $45.89 \%$ in purely viscous glycerin flooding process to $54.12 \%, 51.59 \%$, and $49.02 \%$ in viscoelastic polymer flooding process, respectively. The ratio of elastic contribution on the oil recovery decreases with an increase in the water sweep efficiency. The elastic contribution ratio decreases from $9.57 \%$ in water displacement sweep efficiency of $20 \%$ to $6.39 \%$ in water displacement sweep efficiency of $60 \%$. This phenomenon can reflect the fact that the sooner the polymer is injected, the greater the ultimate oil recovery and the elastic contribution. However, the water sweep efficiency will be the optimum value when considering the economic benefits in an oil field industry application [32, 33, 55, 56]. 


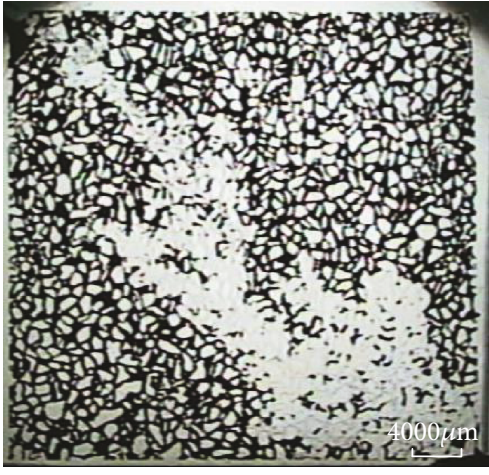

(a) Water flooding

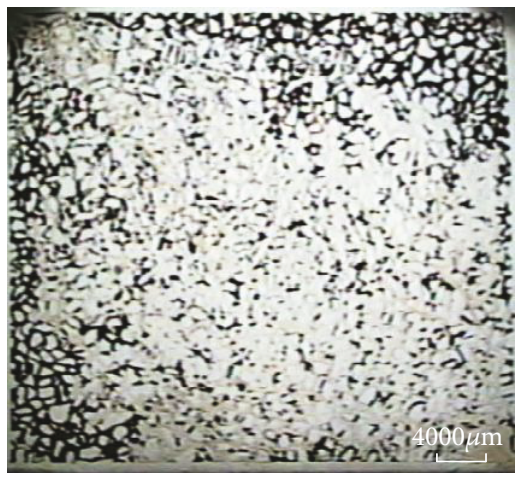

(b) Glycerin flooding

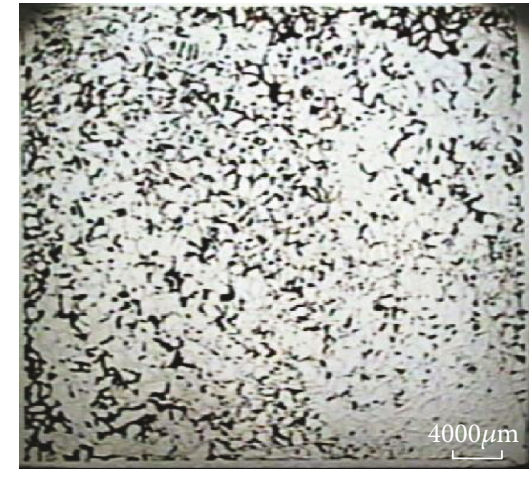

(c) Polymer flooding

FIGURE 8: Residual oil distribution of glycerin flooding and viscoelastic polymer flooding with the same viscosity (40 mPa.s) at a water displacement sweep efficiency of $20 \%$ (the dark area is oil, and the lighter the color is, the lower the saturation is; the light area represents the displacing fluid).

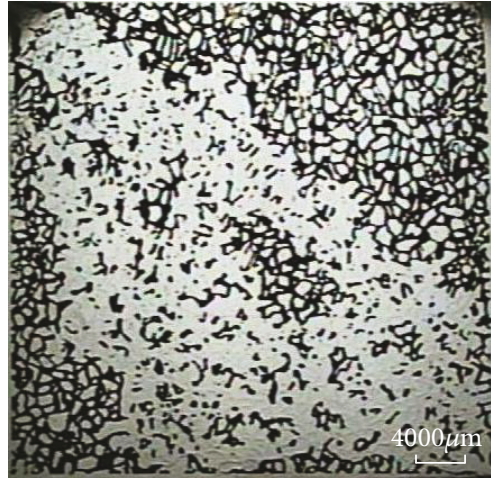

(a) Water flooding

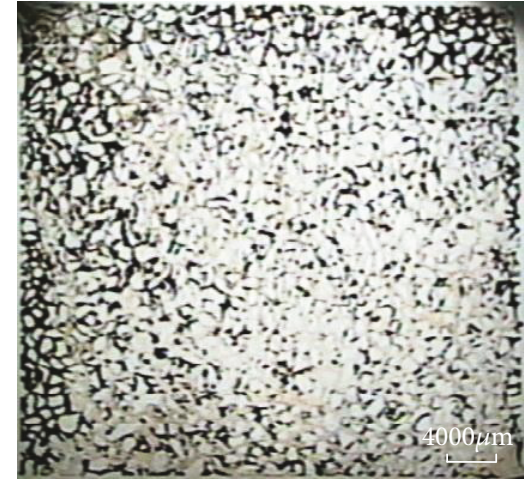

(b) Glycerin flooding

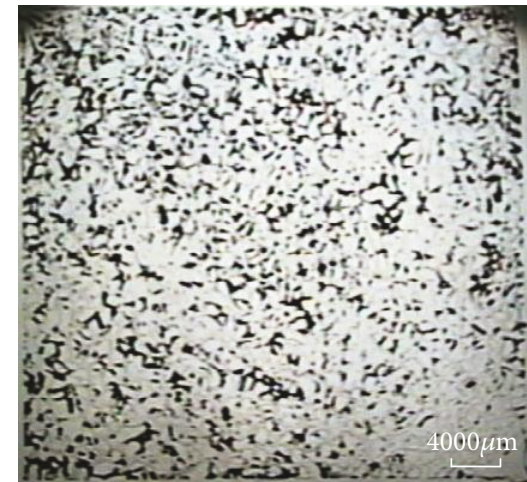

(c) Polymer flooding

FIGURE 9: Residual oil distribution of glycerin flooding and viscoelastic polymer flooding with the same viscosity (40 mPa.s) at a water displacement sweep efficiency of $60 \%$ (the dark area is oil, and the lighter the color is, the lower the saturation is; the light area represents the displacing fluid).

TABLE 2: Displacement efficiency of glycerin and viscoelastic polymer with the same viscosity (40 mPa.s) at different water displacement sweep efficiency levels.

\begin{tabular}{lccr}
\hline $\begin{array}{l}\text { Water displacement } \\
\text { sweep efficiency (\%) }\end{array}$ & Glycerin flooding & $\begin{array}{c}\text { Ultimate oil recovery (\%) } \\
\text { Viscoelastic polymer flooding }\end{array}$ & $\begin{array}{c}\text { Elastic contribution to } \\
\text { oil recovery (\%) }\end{array}$ \\
\hline 20 & 48.94 & 54.12 & 9.57 \\
40 & 47.26 & 51.59 & 8.39 \\
60 & 45.89 & 49.02 & 6.39 \\
\hline
\end{tabular}

The results are in agreement with the existing understanding that the viscoelastic behavior of the polymer plays an indispensable mechanism in chemical flooding EOR process. The previous studies reported the elastic contribution on low-viscosity oil through an etched-glass experiment comparing the recovery after glycerin flooding and showed that the oil recovery after polymer flooding increases $20 \%$ and that the ratio of elastic contribution on the low viscosity recovery can reach $10.61 \%[52,53,57]$. Obviously, the maximum elastic contribution ratio on the oil recovery is $9.57 \%$ in this study, which reveals that, although the elastic contribution to low-viscosity oil is greater than that for medium viscosity oil, the effect of elasticity on medium viscosity oil recovery cannot be underestimated.

\section{Core Flooding Experiments}

Based on the microvisual experiments, the core flooding experiments were further carried out, and the understanding on the viscoelastic behavior of polymer flooding in medium viscosity oil recovery were validated, where the displacement fluids were also glycerin and polymer solutions of the same viscosity. 
3.1. Experimental Materials and Methods. The oil used in this experiment is the same with that in the above microvisual experiments, with a viscosity of $70 \mathrm{mPa} \cdot \mathrm{s}$ at $65^{\circ} \mathrm{C}$. The displacement fluid includes AP-P4 hydrophobically associating water-soluble polymers and glycerin solutions, where the viscosity of both fluids was $40 \mathrm{mPa} \cdot \mathrm{s}$ at $65^{\circ} \mathrm{C}$, and the particulates and agglomerates were filtered by a sand core funnel of G1 type with apertures of $20 \sim 30 \mu \mathrm{m}$ from the solutions. The natural cores were sampled from Daqing Oilfield, and they were extracted for approximately 72 hours using a compound solvent (benzene/alcohol $=3: 1$ ) and were then dried at a temperature of $105^{\circ} \mathrm{C}$ for 4 hours. The cores are cylindrical shapes with diameters of $25 \mathrm{~mm}$ and lengths of approximately $80 \mathrm{~mm}$. The average effective permeability and porosity of the cores were $2000 \times 10^{-3} \mu \mathrm{m}^{2}$ and $28 \%$, respectively. The pressure gradient, from low to high, was constant during the core flooding experiment. We injected brine to displace the oil first and recorded the fluid production in the effluent at a steady flow, and the oil saturation can be obtained. Then, we repeated the core flooding experiments using glycerin or polymer solutions for oil displacement, and the corresponding oil saturation were calculated.

3.2. Experimental Results and Discussion. To obtain oil saturation with different numbers of capillaries, in this study, the number of capillaries was defined as

$$
\mathrm{Nc}=\frac{K \nabla P}{\sigma}
$$

where $\mathrm{Nc}$ is the number of capillaries; $K$ is the permeability of the core, $\mathrm{m}^{2} ; \nabla P$ is the pressure gradient, $\mathrm{Pa} / \mathrm{m}$; and $\sigma$ is the interfacial tension, $\mathrm{N} / \mathrm{m}$.

Considering that the interfacial tension for brine oil was $4 \mathrm{mN} / \mathrm{m}$ as tested using a rotating drop method in this study, the interfacial tension for glycerin oil and polymer oil was $5.8 \mathrm{mN} / \mathrm{m}$ and $4.8 \mathrm{mN} / \mathrm{m}$, respectively. The capillary desaturation curves can be acquired. As shown in Figure 10, the capillary desaturation curves can be divided into two stages. At the first stage, the oil saturation after glycerin or polymer solution flooding decreases sharply compared with that after water flooding at the same number of capillaries. The reason for which is the difference of mobility ratio of these displacement fluids, which play an important role in desaturating. At the second stage, for a larger number of capillaries, the oil saturation after polymer flooding decreases sharply in comparison with that after glycerin flooding owing to the elasticity of the polymer solutions, and for the flow of a porous medium, the polymer solutions can exhibit a shear-thickening and more oil can be displaced, which can reduce the oil saturation and enhance the oil recovery. The results also indicate that the oil recovery after brine flooding is $33.08 \%$, the oil recovery after glycerin flooding is $40.89 \%$, and the oil recovery after polymer solution flooding can reach $48.43 \%$. Compared with the purely viscous glycerin flooding, oil recovery after viscoelastic polymer flooding is enhanced $7.54 \%$, and the elastic contribution to oil recovery can reach $15.51 \%$. Moreover, the pores in the core are three-dimensional and more complex than in the etched-glass model, and the elasticity

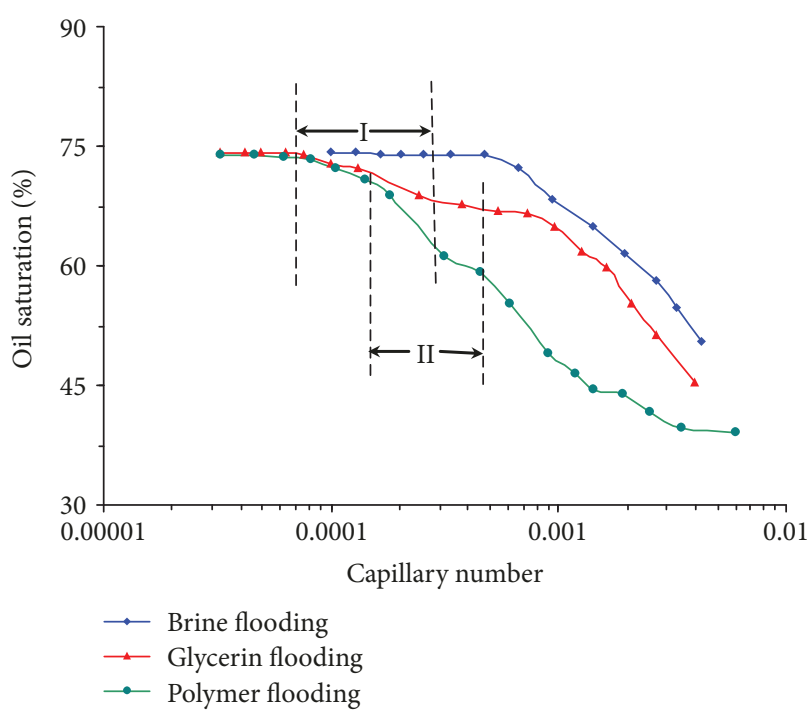

FIgURE 10: Capillary desaturation curves for the core flooding experiments.

of the polymer solutions plays a more important role. It can be concluded that the elastic contribution ratio in the actual reservoir is greater than that in the pore-scale and corescale models.

\section{Conclusion}

Both etched-glass and core flooding experiments were conducted in this study, and with regard to the elasticity of the polymer solution and the elastic contribution on the medium viscosity oil recovery were revealed, the following can be concluded:

(1) In the microvisual experiment, a clear asymmetrical "U" shape of the residual oil interface after polymer flooding can be seen downstream and moving deeper to the dead end owing to the elastic effect. However, the residual oil interface after glycerin flooding is different and shows a symmetrical " $U$ " shape

(2) The incremental oil recovery by elasticity can reach $6.0 \%$, and the ratio of elastic contribution on the oil recovery is $10.7 \%$ based on the direct polymer flooding experiment using etched-glass model. In the experiments on the injection of polymer or glycerin after water flooding, the oil recovery after polymer flooding is higher than that after glycerin flooding owing to the elastic effect at different water sweep efficiencies. The ratio of elastic contribution on the oil recovery increases with the decrease in the water sweep efficiency. Compared with previous knowledge, the elastic contribution to medium viscosity oil is lower than that for low-viscosity oil

(3) At the same number of capillaries, a reduction in the residual oil saturation can be realized through a better mobility ratio and shear-thickening owing to the elasticity effect. Compared with the oil recovery using 
brine flooding, the ratio of elastic contribution on medium viscosity oil reached $15.51 \%$ during the core flooding experiments. It is greater than that in the pore-scale and core-scale models, and this understanding is significant for promoting the application of viscoelastic polymer flooding process in medium viscosity oil reservoir and accelerating nonconventional petroleum development and production efficiently

(4) Intuitively, the elasticity effect on the medium viscosity oil can be observed in the microvisual experiments, and the results are comparable with the findings from previous low-viscosity oil experimental study. It can be concluded that the elasticity can improve medium viscosity oil recovery. It is essential to employ a polymer solution with greater elasticity in the actual medium viscosity oil development. Nevertheless, it should be noted that there is a nonnegligible repeatability standard deviation in micromodel experiments, and the numerical simulation method is potential to further understand the underlying mechanism and the role of viscoelastic polymer flooding in enhancing medium viscosity oil recovery

\section{Data Availability}

Both the displacement efficiency data and the oil saturation data used to support the findings of this study are included within the article. The microvisual experimental data used to support the findings of this study are currently restricted by the National Natural Science Funds for Young Scholars of China in order to protect the privacy of the related patients. However, all these data are available from Huiying Zhong (Email: zhhy987@126.com) for researchers who meet the criteria for access to confidential data.

\section{Conflicts of Interest}

The authors declare that they have no conflicts of interest.

\section{Acknowledgments}

This work presented in this paper was financially supported by the National Natural Science Funds for Young Scholars of China (Grant no. 51604079) and the Natural Science Foundation of Heilongjiang Province (Grant no. E2017012). The Natural Science Foundation of Heilongjiang Province (Grant no. E2016015) and the University Nursing Program for Young Scholars with Creative Talents in Heilongjiang Province (Grant no. UNPYSCT-2016126) are gratefully acknowledged.

\section{References}

[1] B. V. Shenoy, "Forecasting crude oil prices," Economic \& Political Weekly, vol. 53, no. 19, pp. 11-14, 2018.

[2] Y. Liu, J. Li, Z. Wang, S. Wang, and Y. Dong, "The role of surface and subsurface integration in the development of a high-pressure and low-production gas field," Environmental Earth Sciences, vol. 73, no. 10, pp. 5891-5904, 2015.

[3] X. Wu, H. Pu, K. Zhu, and S. Lu, "Formation damage mechanisms and protection technology for Nanpu nearshore tight gas reservoir," Journal of Petroleum Science and Engineering, vol. 158, pp. 509-515, 2017.

[4] M. Ma, S. Chen, and J. Abedi, "Modeling the density, solubility and viscosity of bitumen/solvent systems using PC-SAFT," Journal of Petroleum Science and Engineering, vol. 139, pp. 1-12, 2016.

[5] H. Singh and J. Cai, "Screening improved recovery methods in tight-oil formations by injecting and producing through fractures," International Journal of Heat and Mass Transfer, vol. 116, pp. 977-993, 2018.

[6] Z. Rui, X. Wang, Z. Zhang et al., "A realistic and integrated model for evaluating oil sands development with steam assisted gravity drainage technology in Canada," Applied Energy, vol. 213, pp. 76-91, 2018.

[7] Y. Guo, Y. Liang, M. Cao et al., "Flow behavior and viscous-oil-microdisplacement characteristics of hydrophobically modified partially hydrolyzed polyacrylamide in a repeatable quantitative visualization micromodel," SPE Journal, vol. 22, no. 5, pp. 1448-1466, 2017.

[8] W. Zhou, M. Dong, and S. Chen, "Investigation of initial water mobility and its effects on SAGD performance in bitumen reservoirs and oil sands," Journal of Petroleum Science and Engineering, vol. 135, pp. 39-49, 2015.

[9] S. Doorwar and K. K. Mohanty, "Viscous-fingering function for unstable immiscible flows (includes associated Erratum)," SPE Journal, vol. 22, no. 1, pp. 19-31, 2017.

[10] S. Doorwar and K. K. Mohanty, "Extension of the dielectric breakdown model for simulation of viscous fingering at finite viscosity ratios," Physical Review E, vol. 90, no. 1, article 013028, 2014.

[11] E. Amirian, M. Dejam, and Z. Chen, "Performance forecasting for polymer flooding in heavy oil reservoirs," Fuel, vol. 216, pp. 83-100, 2018.

[12] Y. Liu and G. Chen, "Optimal parameters design of oilfield surface pipeline systems using fuzzy models," Information Sciences, vol. 120, no. 1-4, pp. 13-21, 1999.

[13] J. Wang, L. Feng, M. Steve, X. Tang, T. E. Gail, and H. Mikael, "China's unconventional oil: a review of its resources and outlook for long-term production," Energy, vol. 82, pp. 31-42, 2015.

[14] R. F. Meyer and E. D. Attanasi, "Heavy oil and natural bitumen-strategic petroleum resources," WORLD, vol. 434, pp. 650-657, 2003.

[15] J. Cai, L. Zhang, Y. Ju, G. Pia, and Z. Zhang, “An introduction to fractal-based approaches in unconventional reservoirs-part I," Fractals, vol. 26, no. 2, article 1802001, 2018.

[16] R. Seright, "Potential for polymer flooding reservoirs with viscous oils," SPE Reservoir Evaluation \& Engineering, vol. 13, no. 4, pp. 730-740, 2010.

[17] D. Wang, R. S. Seright, Z. Shao, and J. Wang, "Key aspects of project design for polymer flooding at the Daqing oilfield," SPE Reservoir Evaluation \& Engineering, vol. 11, no. 6, pp. 1117-1124, 2008.

[18] Z. Wang, X. Le, Y. Feng, and C. Zhang, "The role of matching relationship between polymer injection parameters and reservoirs in enhanced oil recovery," Journal of Petroleum Science and Engineering, vol. 111, pp. 139-143, 2013. 
[19] A. Clarke, A. M. Howe, J. Mitchell, J. Staniland, and L. A. Hawkes, "How viscoelastic-polymer flooding enhances displacement efficiency," SPE Journal, vol. 21, no. 3, pp. 06750687, 2016.

[20] Z. Rui, F. Peng, K. Ling, H. Chang, G. Chen, and X. Zhou, "Investigation into the performance of oil and gas projects," Journal of Natural Gas Science and Engineering, vol. 38, pp. 12-20, 2017.

[21] J. J. Sheng, B. Leonhardt, and N. Azri, "Status of polymerflooding technology," Journal of Canadian Petroleum Technology, vol. 54, no. 2, pp. 116-126, 2015.

[22] B. L. Knight and J. S. Rhudy, "Recovery of high-viscosity crudes by polymer flooding," Journal of Canadian Petroleum Technology, vol. 16, no. 4, 1977.

[23] H. Saboorian-Jooybari, M. Dejam, and Z. Chen, "Heavy oil polymer flooding from laboratory core floods to pilot tests and field applications: half-century studies," Journal of Petroleum Science and Engineering, vol. 142, pp. 85-100, 2016.

[24] A. Z. Abidin, T. Puspasari, and W. A. Nugroho, "Polymers for enhanced oil recovery technology," Procedia Chemistry, vol. 4, pp. 11-16, 2012.

[25] J. Wang and M. Dong, "Optimum effective viscosity of polymer solution for improving heavy oil recovery," Journal of Petroleum Science and Engineering, vol. 67, no. 3-4, pp. 155-158, 2009.

[26] A. Maghzi, R. Kharrat, A. Mohebbi, and M. H. Ghazanfari, "The impact of silica nanoparticles on the performance of polymer solution in presence of salts in polymer flooding for heavy oil recovery," Fuel, vol. 123, pp. 123-132, 2014.

[27] Z. Wang, Y. Liu, X. Le, and H. Yu, "The effects and control of viscosity loss of polymer solution compounded by produced water in oilfield development," International Journal of Oil, Gas and Coal Technology, vol. 7, no. 3, pp. 298-307, 2014.

[28] E. Delamaide, A. Zaitoun, G. Renard, and R. Tabary, "Pelican lake field: first successful application of polymer flooding in a heavy-oil reservoir," SPE Reservoir Evaluation \& Engineering, vol. 17, no. 3, pp. 340-354, 2014.

[29] R. G. Santos, W. Loh, A. C. Bannwart, and O. V. Trevisan, “An overview of heavy oil properties and its recovery and transportation methods," Brazilian Journal of Chemical Engineering, vol. 31, no. 3, pp. 571-590, 2014.

[30] E. Delamaide, "Exploring the upper limit of oil viscosity for polymer flood in heavy oil," in SPE Improved Oil Recovery Conference, Tulsa, Oklahoma, USA, April 2018.

[31] F. R. Wassmuth, K. Green, W. Arnold, and N. Cameron, "Polymer flood application to improve heavy oil recovery at East Bodo," Journal of Canadian Petroleum Technology, vol. 48, no. 2, pp. 55-61, 2009.

[32] H. Zhong, W. Zhang, Y. Liu, and H. Yin, "The micro-flow mathematical model study on viscoelastic polymer displacement viscous oil," Earth Science, vol. 42, no. 8, pp. 13641372, 2017.

[33] S. Zhou, "Exploration and practice of offshore oilfield effective development technology," Engineering Sciences, vol. 11, no. 10, pp. 55-60, 2009.

[34] V. V. Bulaev, S. N. Zakirov, and E. S. Zakirov, "Possibility of the development of a high-viscous oil reservoir by water flooding," Doklady Earth Sciences, vol. 407, no. 1, pp. 205-208, 2006.

[35] Z. Rui, K. Cui, X. Wang et al., "A quantitative framework for evaluating unconventional well development," Journal of
Petroleum Science and Engineering, vol. 166, pp. 900-905, 2018.

[36] E. Ghoodjani, R. Kharrat, M. Vossoughi, and S. H. Bolouri, “A review on thermal enhanced heavy oil recovery from fractured carbonate reservoirs," Journal of Petroleum \& Environmental Biotechnology, vol. 2, no. 2, p. 109, 2011.

[37] X. Xin, Y. Li, G. Yu et al., "Non-Newtonian flow characteristics of heavy oil in the Bohai Bay oilfield: experimental and simulation studies," Energies, vol. 10, no. 11, p. 1698, 2017.

[38] H. Zhong, W. Zhang, H. Yin, and H. Liu, "Study on mechanism of viscoelastic polymer transient flow in porous media," Geofluids, vol. 2017, Article ID 8763951, 8 pages, 2017.

[39] K. Tong, B. Li, W. Dai et al., "Sparse well pattern and highefficient development of metamorphic buried hills reservoirs in Bohai Sea area, China," Petroleum Exploration and Development, vol. 44, no. 4, pp. 625-635, 2017.

[40] H. Zhong, Y. Li, W. Zhang, H. Yin, J. Lu, and D. Guo, "Microflow mechanism of oil displacement by viscoelastic hydrophobically associating water-soluble polymers in enhanced oil recovery," Polymer, vol. 10, no. 6, p. 628, 2018.

[41] R. S. Seright, "How much polymer should be injected during a polymer flood? Review of previous and current practices," SPE Journal, vol. 22, no. 1, pp. 001-018, 2017.

[42] F. Aktas and T. Clemens, "Viscous oil displacement via aqueous associative polymers," in SPE Symposium on Improved Oil Recovery, Tulsa, Oklahoma, USA, April 2008.

[43] S. Doorwar and K. K. Mohanty, "Viscous fingering during non-thermal heavy oil recovery," in SPE Annual Technical Conference and Exhibition, Denver, Colorado, USA, OctoberNovember 2011.

[44] A. N. El-hoshoudy, S. E. M. Desouky, M. Y. Elkady, A. M. Al-Sabagh, M. A. Betiha, and S. Mahmoud, "Hydrophobically associated polymers for wettability alteration and enhanced oil recovery-article review," Egyptian Journal of Petroleum, vol. 26, no. 3, pp. 757-762, 2017.

[45] D. Janiga, R. Czarnota, J. Stopa, P. Wojnarowski, and P. Kosowski, "Performance of nature inspired optimization algorithms for polymer enhanced oil recovery process," Journal of Petroleum Science and Engineering, vol. 154, pp. 354-366, 2017.

[46] J. Lu and G. A. Pope, "Optimization of gravity-stable surfactant flooding," SPE Journal, vol. 22, no. 2, pp. 480-493, 2017.

[47] K. Sandengen, K. Melhuus, and A. Kristoffersen, "Polymer 'viscoelastic effect'; does it reduce residual oil saturation," Journal of Petroleum Science and Engineering, vol. 153, pp. 355-363, 2017.

[48] Z. Wang, T. Yu, X. Lin, X. Wang, and L. Su, "Chemicals loss and the effect on formation damage in reservoirs with ASP flooding enhanced oil recovery," Journal of Natural Gas Science and Engineering, vol. 33, pp. 1381-1389, 2016.

[49] M. Dejam, "Dispersion in non-Newtonian fluid flows in a conduit with porous walls," Chemical Engineering Science, vol. 189, pp. 296-310, 2018.

[50] D. Wang, H. Xia, Z. Liu, and Q. Yang, "Study of the mechanism of polymer solution with visco-elastic behavior increasing microscopic oil displacement efficiency and the forming of steady "oil thread" flow channels," in Proceedings of SPE Asia Pacific Oil and Gas Conference and Exhibition, Jakarta, Indonesia, April 2001. 
[51] J. Wang and M. Dong, "A laboratory study of polymer flooding for improving heavy oil recovery," in Canadian International Petroleum Conference, Calgary, Alberta, June 2007.

[52] H. Xia, D. Wang, J. Wu, and F. Kong, "Elasticity of HPAM solutions increases displacement efficiency under mixed wettability conditions," in Proceedings of SPE Asia Pacific Oil and Gas Conference and Exhibition, Perth, Australia, October 2004.

[53] H. Xia, D. Wang, G. Wang, W. Ma, H. Deng, and J. Liu, "Mechanism of the effect of micro-forces on residual oil in chemical flooding," in SPE Symposium on Improved Oil Recovery, Tulsa, Oklahoma, USA, April 2008.

[54] E. C. M. Vermolen, M. J. T. van Haasterecht, and S. K. Masalmeh, "A systematic study of the polymer visco-elastic effect on residual oil saturation by core flooding," in SPE EOR Conference at Oil and Gas West Asia, Muscat, Oman, March-April 2014.

[55] M. Zallaghi, R. Kharrat, and A. Hashemi, "Improving the microscopic sweep efficiency of water flooding using silica nanoparticles," Journal of Petroleum Exploration and Production Technology, vol. 8, no. 1, pp. 259-269, 2018.

[56] Z. Rui, T. Guo, Q. Feng, Z. Qu, N. Qi, and F. Gong, "Influence of gravel on the propagation pattern of hydraulic fracture in the glutenite reservoir," Journal of Petroleum Science and Engineering, vol. 165, pp. 627-639, 2018.

[57] H. Xia, D. Wang, G. Wang, and F. Kong, "Elastic behavior of polymer solution to residual oil at dead-end," Acta Petrolei Sinica, vol. 27, no. 2, pp. 72-76, 2006. 

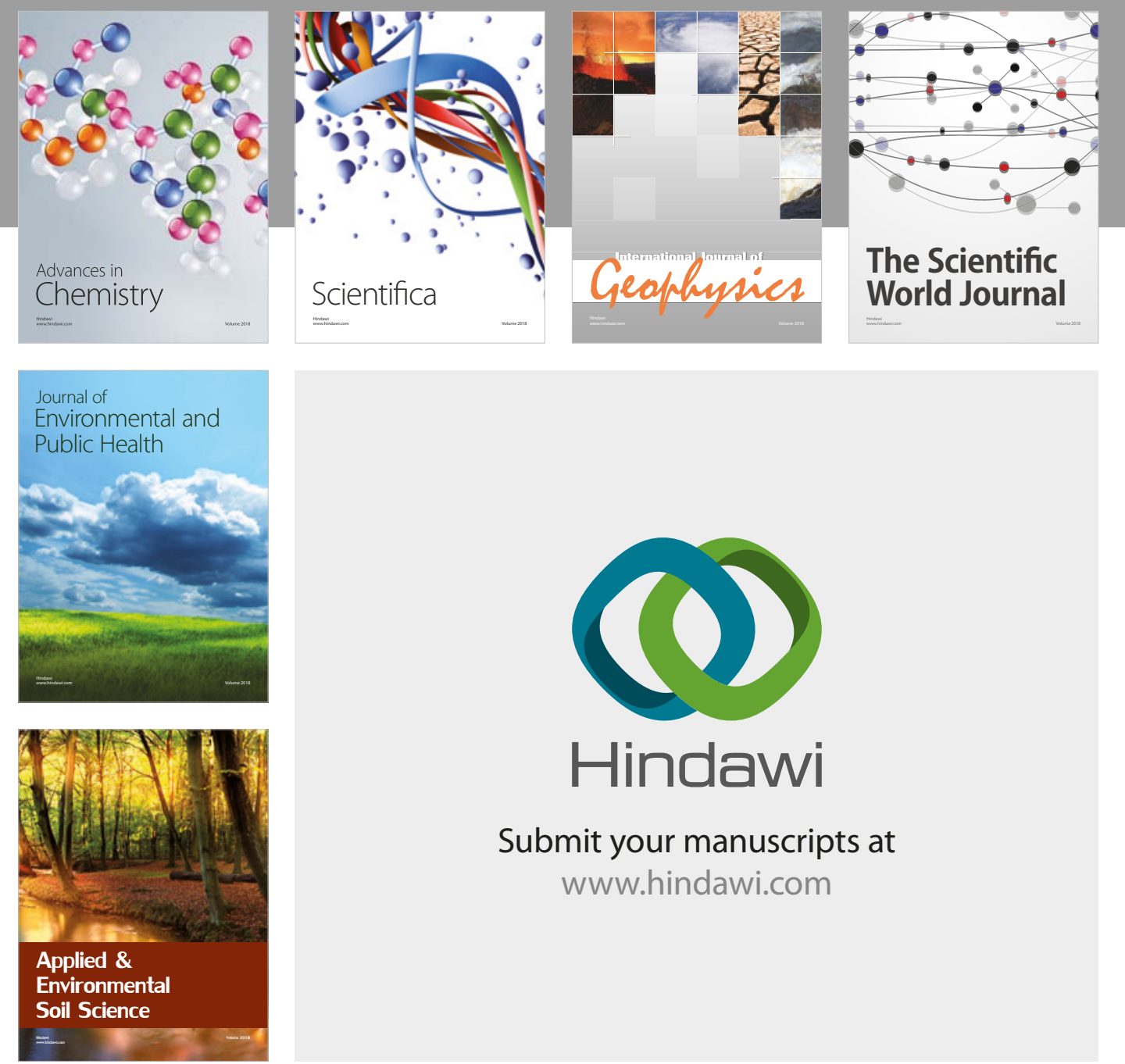

The Scientific

\section{World Journal}
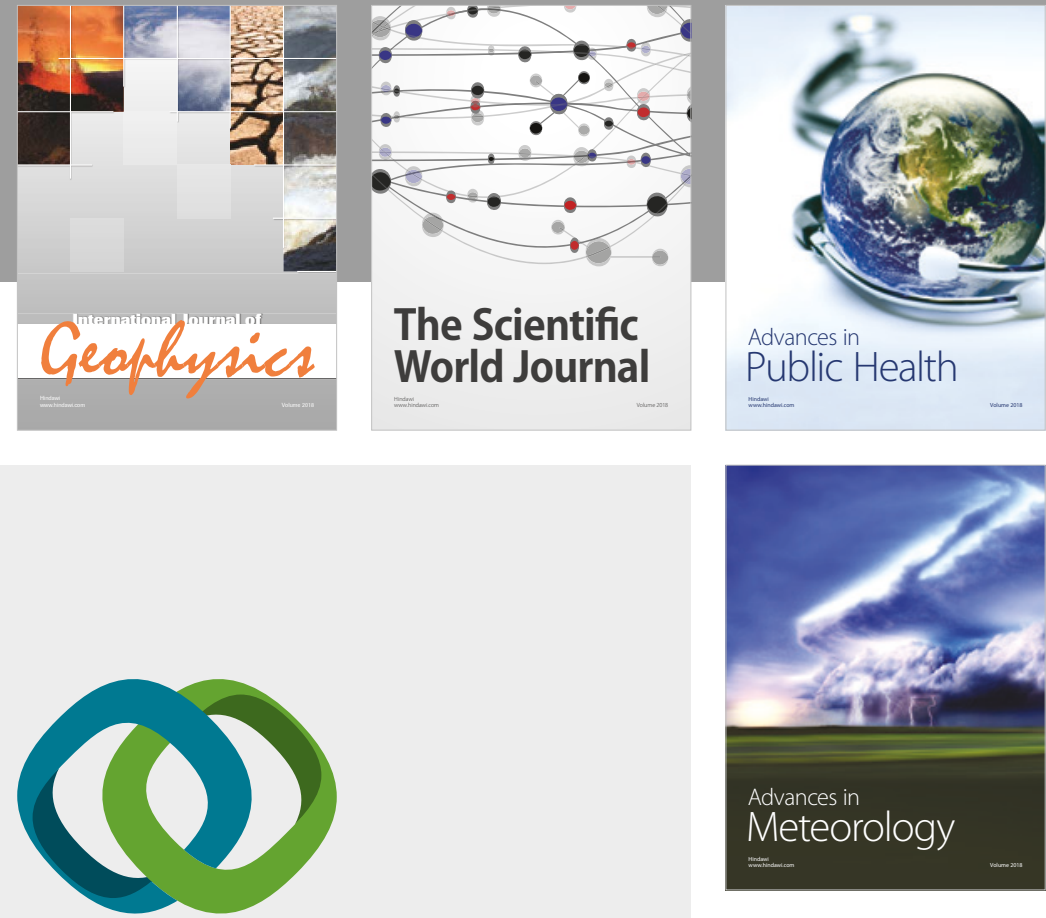

Advan

Public Health

\section{Hindawi}

Submit your manuscripts at

www.hindawi.com
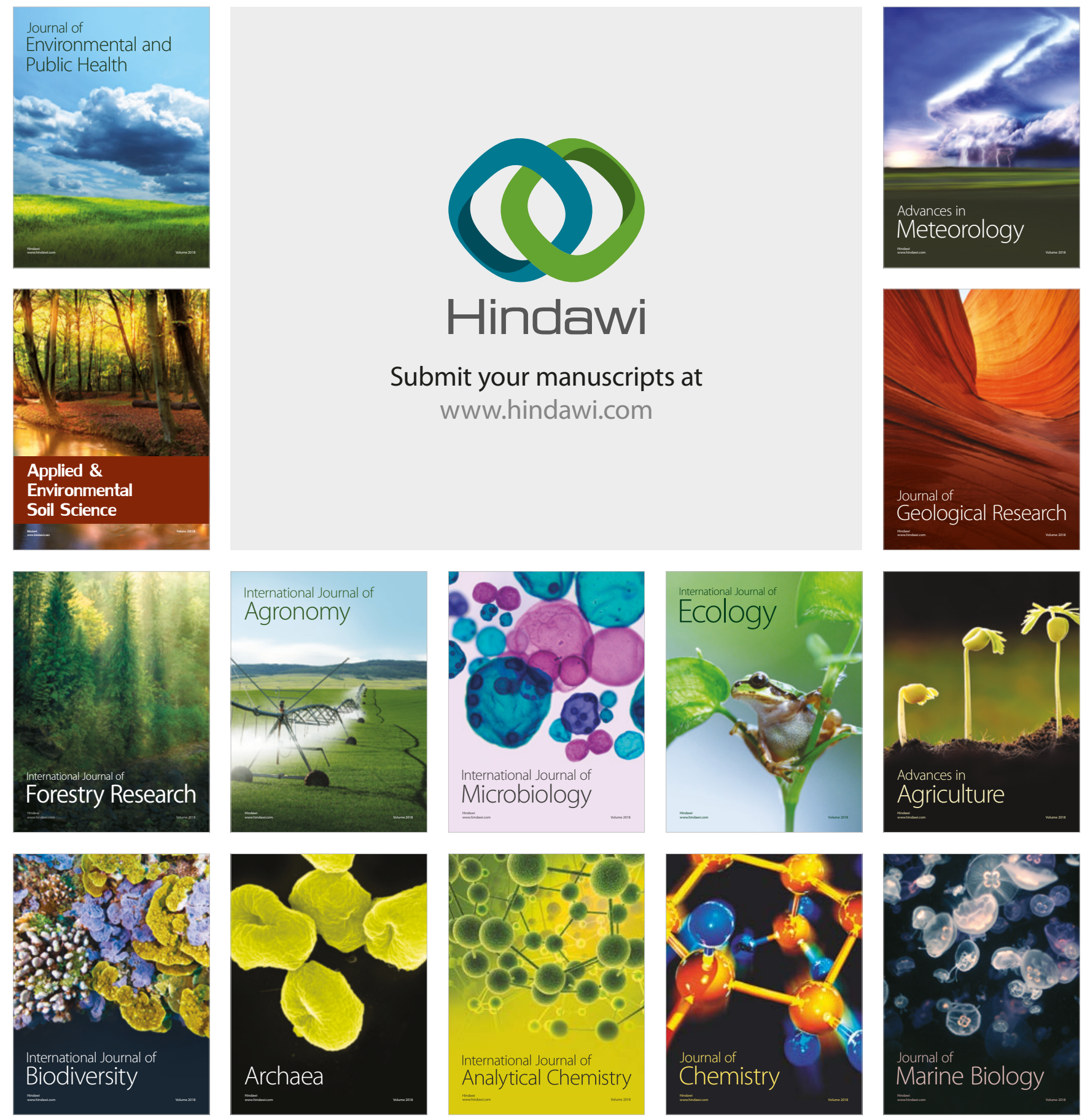